\title{
Editorial
}

\section{Evidence Based Medicine; are we on the same page?}

ARA Rashid

\section{Introduction:}

The term Evidenced Based Medicine (EBM) was coined less than two decades ago and quickly went 'viral'. Over the last decade and a half no decent talk or scientific meeting can capture any ones attention if the word "Evidence Based "does not appear in its programme. Medical Schools the world over are now incorporating the teaching of EBM in their curriculum. Those who neglect its teaching are considered non progressive. Journal articles especially reviews or editorials are more likely to draw the attention of a reader if the word Evidence Based is attached to the title. Clinical Practice Guidelines (CPGs) and Health Policy statements are very much EBM driven. Failing which they become quickly outdated, unquotable and forgotten. Evidenced Based Medicine is not a philosophical concept, it is very practical entity. It is however important to realise that there are also conflicting messages when it comes to interpreting and translating the concept into practice

\section{History of Evidence Based Medicine}

Modern day concept of EBM takes roots from the applications of field epidemiological concepts into clinical practice. Although David Sackett is widely credited with this approach ${ }^{1}$, It is important to remember that the physicians of Andalusia and Umayyad period were the pathfinders. Indeed one of the founders of EBM is the celebrated Ibn Sina (Avicenna) who outlined 7 principles to evaluate effictiveness of a therapeutic approach. He was the first person who emphasied the importance of evaluating a piece of evidence by questioning its internal and external validatity. ${ }^{2}$ Others including Abul Qassim Az Zahrawi
(Albucasis) and $A r$ Razi ( Avorazes ) were credited with the establishment of the most up to research technique and invention in the operating theatre and the laboratory respectively. All of these great pioneers left an important legacy; the art of asking relevant clinical question. Indeed one of the greatest contribution of the golden era of Islam a millennium ago was to inculcate the skills of asking the right question, a cornerstone of EBM. Despite the abundant influence of the Muslims physicians on European physicians in the Renaissance period, their contributions were often forgotten ${ }^{3,4}$. This is especially the case after the lingua franca of medicial advancement changed hand from Arabic to Latin. The last three millennium saw the passing of baton yet again to the English speaking world with most research published in the English language. The first properly conducted clinical trial published in the English literature is on the use of Sanocrysin in the treatment of tuberculosis. ${ }^{5}$

\section{The confusion that is EBM}

Not everyone is happy with EBM. Some call it common sense medicine but as a fellow academic once quipped, not everyone has common sense! David Sackett himself saw this criticism and misunderstanding, coming prompting him to clarify the concept. ${ }^{6}$ One of the contributing factors which triggers confusion is when expert committees themselves give mixed messages in their writing and speech.

How should literature on therapy be interpreted

It is important that practitioners be comfortable with medical literature which is relevant to 
their daily practice. There are various check lists available out there which can assist practitioners to evaluate the medical literature themselves. Practitioners should choose the simplest with the least check list boxes to tick. Most will look at the title of an article and than straight to the conclusion. This can however be the most practical approach when time is the essence. It is more relevant to the practice of medicine if we restrict our search to papers looking at clinical outcomes rather than surrogate end points. Surrogate end points which are clinically relevant is acceptable but time and time again what we thought to be clinically relevant surrogates turns out not to be. Most readers will pay more attention with positive studies at the expense of negative trials. It is however important to remember that negative studies have their role is debunking myths and identifying ineffective treatment. It is important to quickly ask the question whether the patients studied is representative of the one you are treating. Doctors from non Caucasian based practice often argue that since the vast majority of trials were done in a predominantly Caucasian population, the results may not be relevant to their practice. This however has been proven not to be true when major multicentre and multinational trials have been performed where the benefits seen is shown to be robust across regions and ethnicities.

When interpreting research papers especially on therapy, it is important to focus primarily on the primary hypothesis being tested. Everything else is only hypothesis generating and only serve to generate new hypothesis which need to be tested separately. A good example is the study which tested whether the first Angiotensin Receptor Blocker marketed (Losartan) is equally safe to renal function in the elderly patients with heart failure compared to the established treatment at that time; Angiotensin Converting Enzyme Inhibitor (ACE inhibitor)

Captopril called the ELITE $1 .^{7}$ The primary outcome was renal function. Secondary outcome includes a host of cardiovascular outcomes. While the study did show that Losartan is equally safe to the kidney in this patient population, it more interestingly showed that the overall mortality in this high risk patient is reduced by losartan. This has led some practitioners especially heart failure experts to start substituting patients with heart failure from ACE inhibitor to ARB. What the practitioners should have done is to wait to better evidence from a trial which will separately test the hypothesis that ARB prolongs survival in this clinical scenarios. The trial was per- formed ( ELITE 11 ) and it proved that ARB was not better at prolonging survival compared to ACE inhibitors. $^{8}$

Another important issue to remember, on the primary hypothesis, is to be certain whether the study was designed statistically to show equivalence, non -inferiority or superiority. Most sponsors of new drugs will invest in trials to show superiority. The reason is simple. Less patients are required to conduct a superiority trial and therefore less expenditure. At the end of the trial the sponsor wants to show their drug is better than the competitor drug (usually the established treatment of the day). However, once it has been hypothesised that a drug is superior than the competitor, but the study end up to show no difference, one cannot interpret the result as the two drugs being the same in efficacy (also known as equivalence). This is because an equivalent trial will require a much bigger sample size and very few companies will invest in a large trial incurring a big investment just to prove that it is the same as its competitor drug! Equivalence trial has its role in filing for drug registration and in bioequivalence studies but it is unlikely to be designed in clinical outcome trials unless mandated by regulatory authorities. After the ELITE 11 trial, some interpreted the data as meaning that ARB is as good as ACE inhibitor in heart failure, which is not the right interpretation.

Another terminology which has cropped up and sometimes confused readers is the term non inferior. Non inferiority is a term used to show that a drug may not be superior but it is at least non inferior. Statistically speaking, a non -inferiority trial has enough sample size to proof superiority but not large enough to show equivalence. Therefore a non- inferiority trial is usually designed to hopefully also show superiority. Example of trials which were designed for non- inferiority but managed to show both non inferiority and superiority are not many. Most end up showing non inferiority but not superiority. However some authors will go a step further by extrapolating that a positive non inferiority trial is synonymous with showing equivalence. This is also controversial and not widely accepted. In the ONTARGET trial $^{9}$, an ARB (telmisartan) was tested against an ACE inhibitor (ramipril) for non inferiority in high risk cardiovascular patients . The trial manage to prove non inferiority but the authors concluded that telmisartan is equivalent to ramipril . It 
is worth remembering that non -inferiority trials are designed when it is unethical to do placebo control trials. Interestingly a sub study of ONTARGET called TRANSCEND ${ }^{10}$ looked at telmisartan vs placebo in ACE inhibitor intolerant patients hoping to show superiority over placebo. The result turn out to be negative. In other words the conclusion made in ONTARGET is too premature and extrapolative.

Many of us find critically appraising and interpreting medical literature daunting . A convenient way out is to turn to the latest Clinical Practice Guidelines ( CPGs ). We trust that experts who sit in these committee will interpret the papers for us and in the process make our task more bearable. Unfortunately when even CPGs do demonstrate different interpretation of studies. A case in point is the latest guideline on the target blood pressure in treating in the diabetic hypertensive patient. The American Diabetic Association recommend a target of $<140 / 90 \mathrm{mmHg}^{11}$, the European Society of Hypertension $<140 / 85 \mathrm{mmHg}^{12}$, and the Canadian Hypertension Education Programme < 130/80 mmHg. ${ }^{13}$ A closer scrutiny at the references quoted for these differing recommendations, showed that the American recommendation quoted evidence from observational studies, the European quoting sub study of a bigger trial and the Canadian from opinion of the committee. However none of these guidelines quoted the biggest and most relevant trial which looked specifically at BP lowering in the diabetic which managed to achieved an on treatment BP of $135 / 75 \mathrm{mmHg}$ with positive outcomes $^{14}$. Experts must talk the same language and be on the same page. Otherwise many practitioners will end up confused and patient care may be compromised, being derived of evidenced based treatment. ${ }^{15}$

\section{The Lets go back to basics}

Although there are some discordant when EBM is applied to daily practice, uniformity does exist. This can be seen in the trans Atlantic cardiovascular fraternity where Grades of Recommendations and Levels of Evidence has been streamlined and agreed upon. The same cannot be said of other disciplines. In the meantime there are some changes which need to be implemented which may enhance efforts towards greater concordance .

Firstly the teaching of EBM at the undergraduate and post graduate levels needs to be more systematic and should not be a one off approach . It is impor- tant that teaching of EBM should be led by practising clinicians who are role models in translating EBM concepts into practice in the clinics, wards and operating theatres. ${ }^{16,17}$ It should also permeate the curriculum particularly in the clinical years. Secondly the traditional Continuous Professional Development ( CPD )Programme must be better monitored and Evidenced Based. The uncomfortable truth is that many of these CPDs, even done under the auspices of leaned societies, are industry driven. However professional and ethical coexistence is not impossible provided both sides stick as closely as possible to EBM principles. ${ }^{18}$ Credentialing bodies and industry watch dog can help to facilitate this . Editors of journals could insist on a uniform format of reporting clinically important trials which may change practice. Particular attention should be placed on the primary hypothesis tested and conclusion made which should reflect the primary hypothesis. Two recent trials ${ }^{19,20}$ unfortunately concluded differently from the primary hypothesis which serves to confuse the readership further .Guideline committees should try to agree as much as possible on basic principles when writing guidelines. Sometimes contradiction occurs within guidelines. The ESC/ESH guideline for example rank surrogate end point studies at the same levels as evidence from important clinical outcome study in the treatment of hypertensive patients with left ventricular hypertrophy. It also did not quote the study which was specifically designed to look at BP lowering post stroke in recommending anti hypertensive in patients who had suffered a stroke.

\section{Conclusion:}

Evidence Based Medicine is here to stay. Neglecting it or just paying lip service to it will be retrogressive. The science of EBM needs to evolve so that less contradiction and more uniformity exist. Better evidence which is research- driven must also be generated. Clinicians, researchers, funders and policy makers must work in tandem to identify important and as yet unanswered clinical questions which need to be tested in well conducted randomised control trials. Editors of journals should insist on uniformity of reporting when clinically important and potentially practice changing trials are reported. Experts who are invited to give lectures and write reviews or CPGs must stick to the important principles of interpreting trials so that there will be less confusion to the listeners and readers. Teachers of 
EBM both at undergraduate and postgraduate levels must also adhere to these important principles. By adopting all these, it is hope that there will be more uniformity and clarity. Consequently, when it comes to EBM, we will be more likely to be on the same page.

\section{References:}

1. David L. Sackett, R. Brian Haynes, Peter Tugwell. Clinical Epidemiology . A Basic Science for Clinical Medicine . First Edition, 1985. Little, Brown and Company, Boston, USA

2. Christian Gluud . Trials and errors in clinical research. Lancet. 1999; 354 doi:10.1016/50149-6736(08)61345-8

3. Johna S. Marginalisation of ethnic and religious Minorities in Middle Eat history of Medicine : the forgotten contribution to Arabian and Islamic Medicine and Science. Acta Med Hist Adriat 2010;2:203-10

4. Abdul Rashid Abdul Rahman. Increasing Muslim Contribution to Medical Research; Reviving a Lost Legacy. Bangladesh Journal of Medical Science 2010; 9(2) : 59-61. DOI: 10.3329/bjms.v9i2.5653

5. Amberson JB, McMahon BT, Pinner M. A clinical trial of sanocrysin in pulmonary tuberculosis. The American Review of Tuberculosis 1931;24:401-35.

6. Sackett DL, Rosenberg WMC, Gary JAM, Hayes RB, Richardson WS. Evidence based medicine ; what it is and what it isn't. BMJ 1996; 312: 71-2 http://dx.doi.org/ 10.1136/bmj.312.7023.71

7. Pitt B,Segal R, Martinez FA et al Randomised trial of losartan versus captopril in patients over with heart failure ( Evaluation of Losartan in the Elderly study, ELITE). $\quad$ Lancet 1997;349:747-52 http://dx.doi.org/10.1016/S0140-6736(97)01187-2

8. Pitt B, Poole-Wilson P, Segal R et al Effect of losartan compared with captopril on mortality in patients with symptomatic heart failure : randomised trial - the Losartan Heart Failure Survival Study ELITE II. Lancet 2000;355:1582-7 http://dx.doi.org/10.1016/S0140-6736(00)02213-3

9. Yusuf S, Teo KK, Pogue J, et al. Telmisartan, ramipril, or both in patients at high risk for vascular events. $N$ Engl J Med 2008;358:1547-59 http://dx.doi.org/ 10.1056/NEJMoa0801317

10. Yusuf S, Teo K, Anderson C, et al. Effects of the angiotensin receptor blocker telmisartan on cardiovascular events in high-risk patients intolerant to angiotensin-converting enzyme inhibitors: A randomised controlled trial. Lancet 2008;372(9644):117483 http://dx.doi.org/10.1016/S0140-6736(08)61242-8
11. ADA Position paper 2013. Diabetes Care 2013; 36 (1) : S1-S110 ADA 2013

12. $2013 \mathrm{ESH} / \mathrm{ESC}$ Guidelines for the management of arterial hypertension: The Task Force for the management of arterial hypertension of the European Society of Hypertension (ESH) and the European Society of Cardiology (ESC) Eur Heart J 2013;34(28):2159-219 http://dx.doi.org/10.1093/eurheartj/eht151

13. Hackam DG,Quinn RR,Ravani P et al . The 2013 Canadian Hypertension Education Program recommendations for blood pressure measurement, diagnosis, assessment of risk,prevention, and treatment of hypertension. Can J Cardiol 2013;29 (5):528-42 http://dx.doi.org/10.1016/j.cjca.2013.01.005

14. Patel A. ADVANCE Collaborative Group. Effects of a fixed combination of perindopril and indapamide on macrovascular and microvascular outcomes in patients with type 2 diabetes mellitus (the ADVANCE trial): a randomised controlled trial. Lancet 2007;370:829-840 http://dx.doi.org/10.1016/S0140-6736(07)61303-8

15. AR Abdul Rashid Suboptimal Treatment in Chronic Diseases - Time to go Back to Basics. Med J Malaysia 2008;63:185-187

16. Brendan M Reily. Inconvenient truths about effective clinical teaching Lancet 2007; 370:705-711 http://dx.doi.org/10.1016/S0140-6736(07)61347-6

17. Abdul Rashid Abdul Rahman . Evidence Based Medicine; Time to Practise Not Preach. CME Bulletin 1997, Vol 1, pg 1

18. Abdul Rashid Abdul Rahman . Continuing Professional Development And The Pharmaceutical Industry- Education or Marketing . Bangladesh Journal of Medical Science 2013;12(1) :5-9 http://dx.doi.org/10.3329/bjms.v12i1.13347

19. Benjamin M. Scirica, Deepak C. Bhatt, Eugene Braunwald et al. Saxagliptin and Cardiovascular Outcomes in Patients with Type 2 Diabetes Mellitus. $N$ Engl J Med 2013; 369(14):1317-26 http://dx.doi.org/10.1056/NEJMoa1307684

20. William B. White, Christopher Cannon, Simon Heller et al . Alogliptin after Acute Coronary Syndrome in Patients with Type 2 Diabetes. $N$ Engl J Med 2013; 369(14):1327-35 http://dx.doi.org/10.1056/ 